\title{
Effects of dorsal and lateral decubitus on peak expiratory flow in healthy subjects
}

\author{
Heloisa H. Gianinis ${ }^{1}$, Bianca 0. Antunes ${ }^{1}$, Rita C. V. Passarelli ${ }^{1}$, \\ Hugo C. D. Souza ${ }^{2}$, Ada C. Gastaldi ${ }^{2}$
}

\begin{abstract}
Background: One of the measures of the pulmonary function is the peak expiratory flow (PEF) that can be defined as the major flow obtained in an expiratory pressure after a complete inspiration to the level of the total lung capacity. This measure depends on the effort and strength of expiratory muscles, the airway diameter and the lung volume. Objective: To compare the results of the peak expiratory flow in healthy male and female obtained in a seated position and dorsal decubitus (DD), right lateral decubitus (RLD) and left lateral decubitus (LLD). Method: Thirty young subjects with mean age 22.7 years, healthy and non-smokers were included at the study, 15 of male sex. They did spirometry and IPAQ questionnaire to check the normal pulmonary function and physical activity level. The measures of PEF were performed in four positions, being performed 3 measures in which position, in a random order. Statistical analysis was performed according to Student's t test, with significance level set at 5\%. Results: There was a difference between the values obtained in sitting position(481 $\pm 117.1 \mathrm{~L} / \mathrm{min})$ with $\mathrm{DD}(453.2 \pm 116.3 \mathrm{~L} / \mathrm{min})$ and $\mathrm{RLD}(454 \pm 112.9$ $\mathrm{L} / \mathrm{min})(\mathrm{p}<0.05)$, however, did not find a significant difference between the sitting position and LLD (469 $\pm 83 \mathrm{~L} / \mathrm{min})$. Conclusions: Body position affects the values of PEF, with decreasing values in DD and RLD. The LLD can be an alternative to optimize the expiratory flow in situations of constraint to the sitting position.
\end{abstract}

Keywords: peak expiratory flow rate; meter; physical therapy.

\section{HOW TO CITE THIS ARTICLE}

Gianinis HH, Antunes BO, Passarelli RCV, Souza HCD, Gastaldi AC. Effects of dorsal and lateral decubitus on peak expiratory flow in healthy subjects. Braz J Phys Ther. 2013 Sept-Oct; 17(5):435-441. http://dx.doi.org/10.1590/S1413-35552012005000116

\section{Introduction}

Several tests are available to assess pulmonary function. Lung volume and flow are the most commonly used measures. Lung volume does not directly assess pulmonary function; however, changes in lung volumes and flows are associated with pathological respiratory conditions ${ }^{1}$. Pulmonary function tests play a key role in the diagnosis and quantification of the intensity of respiratory disorders and management of patients with pulmonary diseases, both in adult and pediatric populations ${ }^{2}$. The peak expiratory flow (PEF) rate is a measure of pulmonary function that may be defined as the greatest flow assessed in a forced expiration from a full inspiration at total lung capacity level ${ }^{1,2}$.

PEF is dependent on volunteer effort, expiratory muscle strength, airway caliber, lung volume and strength of lung elastic recoil ${ }^{3}$. The muscles activated during inspiration cause the increase in thoracic volume and consequent pleural and alveolar pressure drop to sub-atmospheric values, enabling ambient air, at atmospheric pressure, to move into the lungs. Upon expiration, the thorax and lungs passively return to the rest position moving the air out of the lungs at the expense of their elastic forces. Upon forced expiration, however, several thoracic and abdominal wall muscle groups should be contracted to decrease the thoracic volume ${ }^{4-6}$.

PEF values may be related to the ability of coughing. Effective coughing requires generating high PEF rates at a level sufficient to move secretions from the airways surface. Coughing protects the airways from inhalation of foreign substances in healthy people and is responsible for eliminating the excess mucus in hypersecretory diseases. High flows may be generated by forced contraction of expiratory muscles, which generate high thoracic and abdominal pressure changes ${ }^{6}$. The high intrapulmonary pressure reached from a deep inspiration, glottis closure and contraction

\footnotetext{
${ }^{1}$ Physical Therapist, Ribeirão Preto, SP, Brazil

${ }^{2}$ Department of Biomechanics, Medicine and Rehabilitation of the Locomotor Apparatus, School of Medicine of Ribeirão Preto, Universidade de São Paulo (USP), Ribeirão Preto, SP, Brazil

Received: 07/11/2012 Revised: 01/08/2013 Accepted: 03/15/2013
} 
of expiratory muscles provides high flows in the cough explosive phase, and that high flow transfers kinetic energy from the air to the secretion or foreign body, removing them from the bronchial wall and transporting them into the pharynx or mouth, where they may be removed ${ }^{4}$.

The simplicity of the PEF measuring method is its main advantage and it may be performed using different instruments, including portable devices ${ }^{7,8}$. The portable peak flow meter is a simple, reliable, inexpensive device, which is easy to transport, handle and understand. The gauges of adults typically range from 100 to $850 \mathrm{~L} / \mathrm{min}$ (no less than $100 \mathrm{~L} /$ $\mathrm{min})^{9}$. The satisfactory completion of PEF is volume effort-dependent. The forced expiratory effort should be launched from a neutral position because neck extension increases and flexion decreases PEF through changes in tracheal complacency ${ }^{9}$. At least three measurements should be performed at each session. The maneuver should be repeated until three readings fall within a range of less than $20 \mathrm{~L} / \mathrm{min}$ from each other ${ }^{10}$. The highest value of the three readings should be recorded 9 .

Although PEF measurements are affected by the different devices and measuring methods ${ }^{11}$, some studies show there are no differences between measurements assessed in the sitting or standing up positions ${ }^{12-14}$, while others suggest differences ${ }^{15}$. Regardless of those controversies, the guidelines of international associations ${ }^{16}$ recommend performing the maneuver in the standing up position ${ }^{16}$. However, hospitalized patients, in particular, may have limitations and difficulties in performing the measurement standing up ${ }^{15}$.

It is known that the regional distribution of ventilation in the supine position may be affected by body posture, with a predominance of ventilation in areas dependent on gravity ${ }^{16-19}$. However, the effect of different postures on PEF, particularly relevant for physical therapy, has yielded controversial results. Respiratory therapy uses several techniques that may associate forced expirations, cough and various body positions aiming to remove secretions, with improved pulmonary ventilation and gas exchange ${ }^{20}$.

This study aimed to compare the results of PEF in young and healthy adult men and women assessed in the sitting position with measures assessed in dorsal decubitus (DD), right lateral decubitus (RLD) and left lateral decubitus (LLD).

\section{Method}

This research consisted in a cross-sectional observational study. Young adults were recruited according to the following inclusion criteria: age between 18 and 30 years, nonsmokers, without neurological and/or respiratory diseases, able to adequately perform the maneuvers and not using stimulants.

The study was approved by the Research Ethics Committee of the University Hospital of the School of Medicine of Ribeirão Preto, University of São Paulo (Universidade de São Paulo - USP), Ribeirão Preto, São Paulo (SP), Brazil, HCRP (University Hospital of Ribeirão Preto) process No. 8731/2010. All volunteers read and freely signed the informed consent form.

The physical evaluation of the volunteers was subsequently performed, and data were recorded on an evaluation form, which contained the name, age, vital signs, peripheral oxygen saturation and PEF data. All subjects performed spirometry towards assessing the normality of lung function, and filled out the International Physical Activity Questionnaire $(\mathrm{IPAQ})^{21}$ to measure the level of physical activity.

The evaluations were performed by the same rater, always in the afternoon period.

\section{Spirometry}

Each volunteer performed a rest period of five to ten minutes before the test. The procedure was carefully described and conducted according to the guidelines for pulmonary function tests of $2002^{9}$.

A previously calibrated spirometer (Koko PFT system version 4.11, 2007 nSpire Health, Inc; Pulmonary Data Services, United States) was used for the measurements. The volunteers sat upright, feet flat and head in a neutral position, avoiding flexion and extension, using a nose clip to prevent air from escaping through the nose.

The volunteers were instructed to put the mouthpiece in their mouths to avoid air leakage and breathe at tidal volume. Shortly after, they were instructed to perform a laminar flow inspiration to total lung capacity (TLC), a forced and maximum expiration and again inspiration until TLC.

The maneuver was performed until the volunteer performed three acceptable and two reproducible flow-volume curves, within eight attempts, to ensure the reproducibility of the curves. 


\section{Evaluation of peak expiratory flow}

A Mini Wright ${ }^{\circledR}$ (Clement Clarke International Ltd, England) portable device, with disposable mouthpiece, easily handled and belonging to the institution was used to perform the PEF measurements.

The measurements were performed at four positions: sitting and lying on DD, LLD and RLD. The position at which the volunteer should start the measurements was randomly defined by draw towards avoiding the effect of the order of measures and consequent fatigue in the last measurements.

The volunteers performed three measurements at each position, with one minute of rest between measurements, and the readings should not have more than $20 \mathrm{~L} / \mathrm{min}$ difference between them. The highest value found among the measurements performed was considered the final value.

\section{Statistical analysis}

The variables analyzed followed a normal distribution according to the Shapiro-Wilk test. The sitting position was compared to the DD, LLD and RLD positions according to the paired Student $t$ test, with significance level set at $5 \%$ probability.

\section{Results}

A total of 30 volunteers, with 15 females and 15 males, with a mean age of $22.2 \pm 2.4$ years were studied. The male subgroup mean age was $22.13 \pm 1.9$ and the female subgroup mean age was $22.27 \pm 2.4$ years.

The mean body mass index (BMI) was $26 \pm 4.95$ $\mathrm{Kg} / \mathrm{cm}^{2}$ in the male subgroup and $22.5 \pm 2.28 \mathrm{Kg} / \mathrm{cm}^{2}$ in the female subgroup.

According to the IPAQ, most subjects were classified as sedentary $(n=23)$ or with irregular physical activity $(n=7)$.

The results of spirometry are outlined in Table 1 , showing that all subjects were healthy, with normal lung function test.

The PEF values found in the sitting, DD, LLD and RLD positions for healthy male and female volunteers are shown in Table 2.

Comparing the results found in the whole group or separately for males and females, the sitting position with lying on DD, LLD and RLD positions, the values found in the sitting position were higher than those assessed in DD and RLD ( $\mathrm{p}<0.05)$, albeit without significant differences between the sitting and LLD positions (Figure 1).

\section{Discussion}

The purpose of this study was to evaluate the changes that occur in the values of PEF in healthy adults at different positions. The results suggest a decrease in PEF values at DD and RLD when compared with the sitting position, albeit without significant differences regarding the LLD.

The effect of DD in healthy people on different variables of pulmonary function is already well established in the literature, with a decrease in forced vital capacity (FVC) and forced expiratory volume in one second (FEV1) ${ }^{22}$, in addition to increased airway resistance ${ }^{18}$ and decreased maximal expiratory pressure (MEP) ${ }^{18,23}$.

Regarding PEF in healthy subjects, some authors found decreased values in the supine position ${ }^{24}$, while others found similar values ${ }^{14,15}$. Furthermore, others found a decrease only when the volunteers were in the head down position ${ }^{8}$.

The decrease in at lung volumes and flow rates at DD has already been described in obese subjects with asthma also. Haffejee ${ }^{25}$ studied the effect of supine position on PEF values in asthmatic children, aged between four and 11 years, using the Mini Wright portable meter. A first measurement was performed with the child in orthostatic position, subsequently lying down the child and performing the measurements every 30 minutes for four hours. The results showed a significant decrease in PEF in asthmatic children in the supine position.

A similar effect was also found in obese subjects. Domingos-Benício et al. ${ }^{26}$ compared the FVC, FEV and $\mathrm{FEV}_{1} / \mathrm{FVC}$ values in the standing, sitting and lying down positions in volunteers in the age group from 20 to 40 years, eutrophic and obese, sedentary, by spirometry. They found a $20 \%$ reduction in the FVC of both eutrophic and obese subjects when subjects shift into the lying down position.

Regarding the effect of lateral decubitus (LD) on PEF, our results showed a decrease in the values at RLD, comparable to DD, albeit similar to those at the sitting and LLD positions. These results differ from other authors, who found no differences when comparing the LLD and RLD position ${ }^{22-24}$. 
Table 1. Means and standard deviations of spirometric variables in male volunteers and female.

\begin{tabular}{ccccc}
\hline $\begin{array}{c}\text { Spirometric } \\
\text { variables }\end{array}$ & \multicolumn{2}{c}{ Male } & \multicolumn{2}{c}{ Female } \\
FCV $(\mathrm{L})$ & 5.36 & 0.68 & 3.52 & 0.48 \\
FCV\% & 95.93 & 9.74 & 93.43 & 9.71 \\
FEV1 (L) & 4.5 & 0.49 & 3.38 & 1.30 \\
FEV1\% & 96.60 & 8.20 & 92 & 6.20 \\
FEV1/FCV & 0.84 & 0.07 & 0.9 & 0.05 \\
FEV1/FCV \% & 101.13 & 8.36 & 101 & 5.42 \\
PEF (L/s) & 8.02 & 1.59 & 5.75 & 1.13 \\
PFE\% & 82.13 & 17.93 & 81.71 & 25.71 \\
\hline
\end{tabular}

FVC: forced vital capacity; FEV1: forced expiratory volume in one second; FEV1/FVC: index Tiffenau; PEF: Peak expiratory flow; SD: Standard deviation.

Table 2. Means and standard deviations of peak expiratory flow in $\mathrm{L} / \mathrm{min}$ for males and females in the sitting, supine, left lateral and right lateral position.

\begin{tabular}{ccccc}
\hline \multirow{2}{*}{ Position } & \multicolumn{2}{c}{ Males } & \multicolumn{2}{c}{ Female } \\
& Mean & SD & Mean & SD \\
Sitting & 558 & 116.7 & 404.7 & 45.1 \\
Supine position & 530 & 118.2 & 375.7 & 37.4 \\
$\begin{array}{c}\text { Left lateral } \\
\text { decubitus }\end{array}$ & 545.3 & 132.2 & 393 & 38.7 \\
$\begin{array}{c}\text { Right lateral } \\
\text { decubitus }\end{array}$ & 526.7 & 117 & 382.3 & 39.7 \\
\hline
\end{tabular}

Meysman and Vincken ${ }^{22}$ evaluated the effect of the sitting, DD, RLD and LLD positions on the flow-volume curve, showing that PEF at the sitting position was higher than at decubitus positions and the $\mathrm{FEV}_{1} / \mathrm{PEF}$ ratio was higher in the lateral decubitus positions. The authors explain that diaphragm strength is affected by the supine position, with an increase in intrathoracic blood volume and consequent decrease in lung volume. Furthermore, the size of the pharynx is smaller at DD, given the gravitational force acting on the tongue and soft palate, and LD may decrease the resistance of the upper airways.

Badr et al. ${ }^{23}$ studied the PEF and MEP in 25 healthy adults between 18 and 65 years of age and 11 with chronic airflow limitation. The PEF measurements were performed using a spirometer, and the results showed that the standing position had the highest values, followed by the sitting position. There was no significant difference between the decubitus positions (dorsal and lateral), although the LD values were slightly lower than at supine. The explanation provided by the authors indicates that the dependent hemithorax expandability may have decreased.

Elkins et al. ${ }^{24}$ evaluated PEF and MEP in patients with cystic fibrosis at least 18 years of age, using

\section{$\mathrm{L} / \mathrm{min}$}

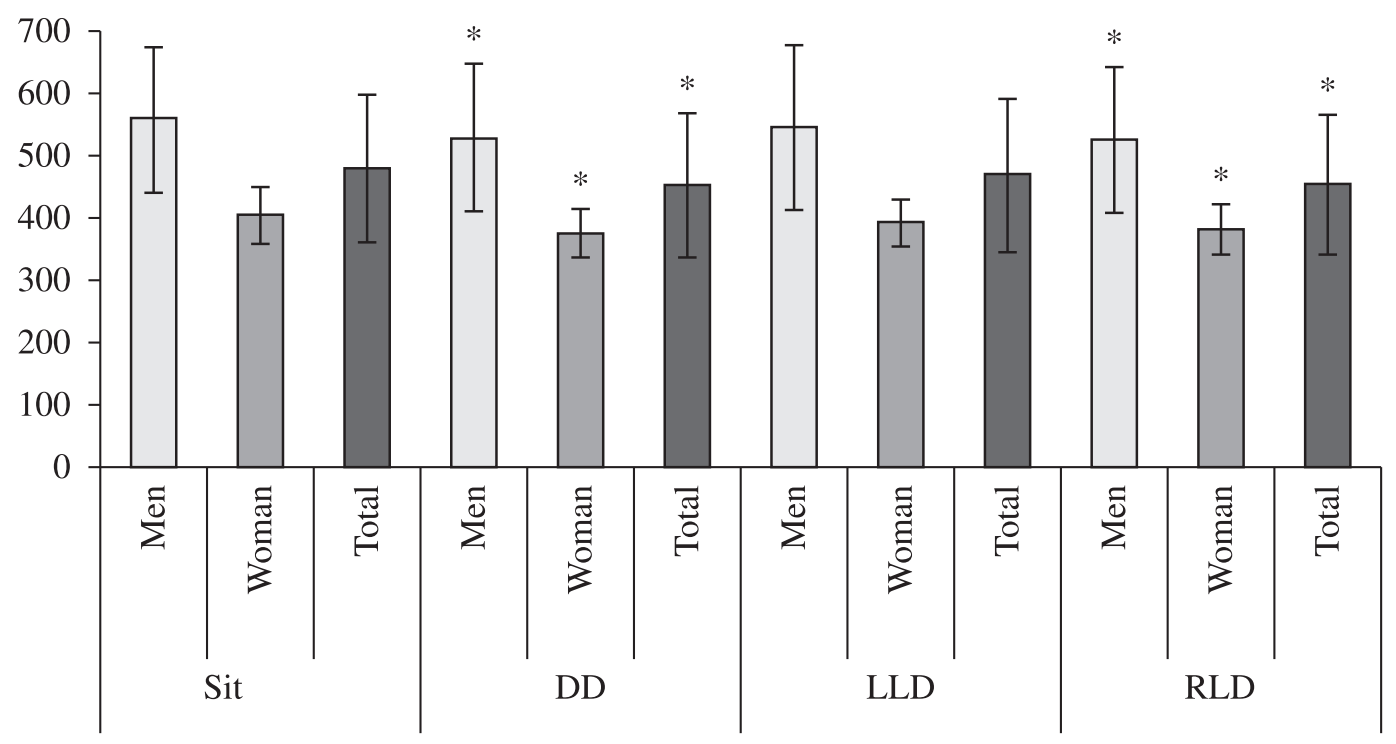

Figure 1. Peak expiratory flow in healthy men and women and for the whole group in the sitting position, supine position (SP), left lateral decubitus (LLD) and right (DLD). * Significant difference compared to sitting position $(\mathrm{p}<0,05)$ 
spirometry and manovacuometry in eight different positions and showed differences in the values of PEF between the positions, with sitting, at $45^{\circ}$, supine, LD and head down tilt showing results significantly lower than both standing and sitting with legs stretched, and the largest difference occurred between the standing $(6.35 \mathrm{~L} / \mathrm{s})$ and supine $(5.79 \mathrm{~L} / \mathrm{s})$ positions. However, they found no differences between the lateral decubitus positions. Conversely, they found that MEP values at LD were significantly lower than standing and sitting on a chair.

The results of Shinde and Shinde ${ }^{8}$, who evaluated eight different positions in healthy adults and patients with chronic obstructive pulmonary disease (COPD) and found no significant trend to higher values of PEF at RLD in relation to LLD in both groups, are also controversial. The authors attributed that result to the higher volume of the right lung and a reduction in the compression of the heart on the lungs at $\mathrm{RLD}^{8}$.

This mechanism does not explain the results of the present study. The LD position enables the forward displacement of the abdominal content. Thus, the authors speculate that the hemidiaphragm, which is in the position dependent on gravity, is elongated, thereby improving its ability to generate pressure, while the non-dependent hemidiaphragm remains less elongated ${ }^{8}$. Conversely, the larger volume of the right lung may have inferably contributed to an increased elongation of the left hemidiaphragm on our results because the diaphragm position was not assessed in any of the studies.

The therapist should define the method of PEF assessment in clinical practice, including patient positioning, enabling to compare PEF values between different periods or between different patients ${ }^{15}$.

Subjects should be positioned with the torso at a higher position to aid the removal of secretions from the airways ${ }^{8,15}$, especially those with reduced ability to cough, considering that PEF is important for performing an effective cough, requiring a peak flow $>180 \mathrm{~L} / \mathrm{min}$ for an effective cough $^{27}$ and the body position may affect the PEF. The flow and rate of air at the time of cough are the main factors responsible for the clearance of airways ${ }^{4,5}$. Thus, it is important to consider that LLD may be an alternative, especially for bedridden patients, although it is crucial to know and understand the physiological effects of different decubitus positions, especially unilateral, and different pathologies on lung function, in the selection process.

Roquejani et al. ${ }^{28}$ analyzed the position effects on the values of muscle strength, which may also affect the PEF. The authors studied the maximal inspiratory and expiratory pressures (MIP and MEP) in healthy adults with ages ranging from 18 to 55 years, using a manovacuometer. The measurements were performed in seven positions and the results of that study showed that significant interactions occurred between the body position and the subject's gender. The highest values of MIP were found at $45^{\circ}$ in women and at RLD in men, whereas the lowest values were found in the Trendelenburg position. However, only the MEP values assessed in the male group were higher, albeit with no effect from the decubitus position.

We chose to show the results separately for men and women, given the predicted differences according to gender in several pulmonary function variables, established by different predictive equations for each gender, although we emphasize that the differences found were confirmed in the whole group and in the male and female groups separately. In our study, we established an age group for inclusion of subjects from 18 to 30 years because aging triggers a reduction of lung elasticity and decreased elastic recoil pressure, contributing to a reduction in respiratory muscle strength, and PEF has its highest peak between 18 and 20 years of age and maintains this level until 30 years of age ${ }^{7,29}$. Only sedentary subjects or those without regular physical activity were evaluated towards reducing the confounding factors because physical activity may contribute to the increase in $\mathrm{PEF}^{5,30}$. Additionally, they were randomly positioned, with no fatigue effect on the results.

Regarding limitations, PEF measurements were performed at different positions using only the portable device; thus, we are not sure whether the results would change when measured by spirometry. Other pulmonary function tests assessing other measures, including residual volume or regional ventilation, were not performed either, or imaging tests towards confirming the position of the dependent hemidiaphragm.

\section{Conclusion}

The body position affects the PEF values in healthy adults, nonsmokers, with a decrease at DD and RLD positions. However, there is no difference between 
the sitting and LLD positions. Thus, the LLD may be an alternative to optimize the expiratory flow in situations restricting the sitting position.

\section{References}

1. Boaventura CM, Amuy FF, Franco JH, Sgarbi ME, Matos LB, Matos LB. Valores de referência de medida de pico de fluxo expiratório máximo em escolares. Arq Med ABC. 2007;32(Supl.2):S30-4.

2. Ruchys VC, Dias RM, Sakurai E, Camargos PAM. Acurácia de medidores do pico de fluxo expiratório (peakflow) da marca MiniWright. J Pediatr. 2000;76:447-52.

3. Quanjer PH, Tammeling GJ, Cotes JE, Pedersen OF, Peslin R, Yernault JC. Lung volumes and forced ventilatory flows: official statement of the European Respiratory Society. Eur Respir J. 1993;6(16):5-40.

4. Freitas FS, Parreira VF, Ibiapina CC. Aplicação clínica do pico de fluxo da tosse: uma revisão de literatura. Fisioter Mov. 2010;23(3):495-502. http://dx.doi.org/10.1590/ S0103-51502010000300016

5. Freitas FS, Ibiapina CC, Alvim CG, Britto RR, Parreira VF. Relação entre força de tosse e nível funcional em um grupo de idosos. Rev Bras Fisioter. 2010;14(6):470-6. http://dx.doi.org/10.1590/S1413-35552010000600004

6. Smith JA, Aliverti A, Quaranta M, McGuinness K, Ketsall A, Earis J, et al. Chest wall dynamics during voluntary and induced cough in healthy volunteers. J Physiol. 2012;590(3):563-574. PMid:22144580 PMCid:PMC3379701.

7. Dikshit MB, Raje S, Agrawal MJ. Lung functions with spirometry: an Indian perspective-I. Peak expiratory flow rates. Indian J Physiol Pharmacol. 2005;49(1):8-18. PMid:15881854.

8. Shinde N, Shinde KJ. Peak expiratory flow rate: Effect of body positions in patients with chronic obstructive pulmonary disease. Indian Journal of Basic \& Applied Medical Research. 2012;1(4):357-362.

9. Pereira CAC, Jasen JM, Barreto SSM, Marinho J, Sulmonett N, Dias RM. Espirometria. In: Diretrizes para testes de função pulmonar. J Pneumol. 2002;28(3):S1-S82.

10. Ayres JG, Turpin PJ. Measurement, recording and analysis of peak flow records. In: Peak flow measurement. Chapman \& Hall Medical; 1997. p. 13-32.

11. Bongers T, O'Driscoll BR. Effects of equipment and technique on peak flow measurements. BMC Pulm Med. 2006; 6(14) [cited 2013 Feb 20]. Available from: http:// www.biomedcentral.com/1471-2466/6/14. http://dx.doi. org/10.1186/1471-2466-6-14

12. Vaswani R, Moy R, Vaswani SK. Evaluation of Factors Affecting Peak Expiratory Flow in Healthy Adults:Is It Necessary to Stand Up? J Asthma. 2005;42:793-794. PMid:16316876. http://dx.doi. org/10.1080/02770900500308528

13. McCoy EK, Thomas LJ, Sowell RS, George C, Finch KC, Tolley EA. An Evaluation of Peak Expiratory Flow Monitoring: A Comparison of Sitting Versus Standing Measurements. J Am Board Fam Med.
2010;23(2):166-170. PMid:20207926. http://dx.doi. org/10.3122/jabfm.2010.02.090120

14. Badaruddin M, Uddin MB, Khatun MF, Ahmad K. Study on Peak Expiratory Flow Rate in Different Positions. Dinajpur Med Col J. 2010;3(1):17-18.

15. Wallace JL, George CM, Tolley EA, Winton JC, Fasanella D, Finch CK, et al. Peak expiratory flow in bed? A comparison of 3 positions. Respir Care. 2013;58(3):494497. PMid:22906434.

16. Global Initiative for Asthma. Global strategy for asthma management and prevention. 2012 [cited 2013 Jan 8]. Available from: http://www.ginasthma.org/guidelinesgina-report-global-strategy-for-asthma.html.

17. Kaneko K, Milic-Emili J, Dolovich MB, Dawson A, Bates DV. Regional distribution of ventilation and perfusion as a function of body position. J Appl Physiol. 1966;21(3):767777. PMid:5912746.

18. Behrakis PK, Baydur A, Jaeger MJ, Milic-Emili J. Lung mechanics in sitting and horizontal body positions. Chest. 1983;83(4):643-6. PMid:6831953. http://dx.doi. org/10.1378/chest.83.4.643

19. Alcoforado L, Pessôa LC F ${ }^{\circ}$, Brandão DC, Galvão AM, Reinaux CM, Andrade AD. Influence of change in lateral decubitus on pulmonary aerosol deposition. Rev Bras Fisioter. 2011;15(4):278-83. PMid:21971723. http:// dx.doi.org/10.1590/S1413-35552011000400004

20. Gomes EL, Postiaux G, Medeiros DR, Monteiro KK, Sampaio LM, Costa D. Chest physical therapy is effective in reducing the clinical score in bronchiolitis: randomized controlled trial. Rev Bras Fisioter. 2012;16(3):2417. PMid:22499404. http://dx.doi.org/10.1590/ S1413-35552012005000018

21. Craig CI, Marshall AL, Sjostrom M, Baumann AE, Booth ML, Ainsworth BE. International Physical Activity Questionnaire: 12-Country Reliability and Validity. Med Sci Sports Exerc. 2003;35(8):1381-1395. PMid:12900694 http://dx.doi.org/10.1249/01.MSS.0000078924.61453.FB

22. Meysman M, Vincken W. Effect of body posture on spirometric values and upper airway obstruction indices derived from the flow-volume loop in young nonobese subjects. Chest. 1998;114(4):1042-7. http://dx.doi. org/10.1378/chest.114.4.1042

23. Badr C, Elkins MR, Ellis ER. The effect of body position on maximal expiratory pressure and flow. Aust J Physiother. 2002;48(2):95-102. PMid:12047207.

24. Elkins MR, Alison JA, Bye PTP. Effect of Body Position on Maximal Expiratory Pressure and Flow in Adults With Cystic Fibrosis. Pediatr Pulmonol. 2005;40:385-391. PMid:16130087. http://dx.doi.org/10.1002/ppul.20287

25. Haffejee IE. Effect of supine posture on peak expiratory flow rates in asthma. Arch Dis Child. 1988;63:127-129. PMid:3348658 PMCid:PMC1778739. http://dx.doi. org/10.1136/adc.63.2.127

26. Domingos-Benício NC, Gastaldi AC, Perecin JC, Avena KM, Guimarães RC, Sologuren MJJ, et al. Medidas espirométricas em pessoas eutróficas e obesas nas posições ortostática, sentada. Rev Assoc Med Bras. 2004;50(2):142-7 PMid:15286860. http://dx.doi. org/10.1590/S0104-42302004000200028 
27. Toussaint M, Boitano LJ, Gathot V, Steen M, Soundon P. Limits of Effective Cough-Augmentation Techniques in Patients With Neuromuscular Disease. Respir Care. 2009;54(3):359-366. PMid:19245730.

28. Roquejani AC, Araújo S, Oliveira RARA, Dragosavac D, Falcão ALE, Terzi RGG, et al. Influência da Posição Corporal na Medida de Pressão Inspiratória Máxima e Pressão Expiratória Máxima em Voluntários Adultos Sadios. Rev Bras Ter Intensiva. 2004;16(4):215-218.

29. Wun YT, Chan MS, Wong NM, Kong AY, Lam TP. A Curvilinear Nomogram of Peak Expiratory Flow Rate for the Young. J Asthma. 2013;50(1):39-44. PMid:23174006. http://dx.doi.org/10.3109/02770903.2012.743152
30. Bemanian MH, Shirkhoda S, Nakhjavani M, Mozafari H. Effect of Swimming on Peak Expiratory Flow Rate of Atopic Children Iran. J Allergy Asthma Immunol. 2009;8(2):121-123.

\section{Correspondence}

\section{Ada Clarice Gastaldi}

Av. Bandeirantes, 3900

CEP 14049-900, Ribeirão Preto, SP, Brasil

e-mail: ada@fmrp.usp.br 